\title{
COMMENTARY
}

\section{Does gender influence outcomes in critically ill patients?}

\author{
Martin K Angele, Sebastian Pratschke and Irshad H Chaudry* \\ See related research by Mahmood et al., http://ccforum.com/content/16/3/R92
}

\begin{abstract}
Investigators continue to debate whether gender plays any role in patient outcome following injury/critical illness. We submit that age and hormonal milieu at the time of injury, rather than gender, are the critical factors influencing patient outcome under those conditions.
\end{abstract}

Mahmood and colleagues [1] performed a retrospective analysis, published in this issue of Critical Care, of 261,255 adult patients admitted to intensive care units (ICUs). The results indicate that women younger than 50 years old had lower ICU mortality in comparison with age-matched men, whereas mortality rate was similar in older patients. Female mortality, compared with male mortality, was increased following coronary artery bypass graft (CABG) surgery but decreased with chronic obstructive pulmonary disease (COPD) exacerbation. Gender-specific mortality rates were not evident for patients with acute coronary syndrome, sepsis, or trauma.

Numerous experimental studies report gender-specific immune and cardiovascular responses [2-4]. Male gender was associated with suppressed immune responses and impaired cardiovascular function as opposed to maintained responses in proestrus females in experimental models of trauma-hemorrhage or sepsis (cecal ligation and puncture). In diestrus mice, immunoprotection was not evident. Proestrus mice are characterized by elevated estrogen plasma levels in comparison with mice in other phases of the estrus cycle. Gender-specific immune responses were reversed in aged mice [2-4].

In contrast, the referenced study [1] did not demonstrate gender-specific outcome in septic and trauma

*Correspondence: ichaudry@uab.edu

Center for Surgical Research, University of Alabama at Birmingham, G094 Volker Hall, 1670 University Boulevard, Birmingham, AL 35294-0019, USA patients in any age group. Similarly, other clinical studies failed to consistently reproduce experimental findings [5]; a large cohort of 22,332 patients with blunt injury did not demonstrate gender-specific outcome [6]. A retrospective analysis of blunt and penetrating trauma at the University of Alabama (Birmingham, AL, USA), however, showed a significantly increased mortality rate in males younger than 50 years of age [7]. Those results are supported by Deitch and colleagues [8], who conducted a prospective cohort analysis ( $\mathrm{n}=$ more than 4,000 trauma patients) that showed that, despite higher Injury Severity Scores (ISSs), females younger than 50 years tolerated trauma better than males did. Higher proinflammatory cytokine levels appear to be responsible for diminished outcome in male victims of trauma [9]. In burn patients, however, young females had an increased mortality rate $[10,11]$, suggesting that different trauma mechanisms (blunt versus burn trauma) alter gender-specific outcome.

In experimental studies, sex hormones have been shown to affect gender-specific immune responses. Male sex hormones are deleterious whereas female hormones are protective $[2-4,12]$. Hormonal status is not evaluated in most clinical studies. To define pre- versus postmenopausal by using a cutoff age of 50 years is inaccurate. Furthermore, the percentage of postmenopausal females on hormone replacement therapy is not defined. According to Hersh and colleagues [13], an estimated $21 \%$ of US women take hormone replacement medication. This should be taken into consideration when analyzing gender-specific outcomes in critically ill patients. Failure to measure hormone plasma levels significantly limits most clinical studies investigating gender differences. In summary, the prevailing hormonal milieu, and not gender, dictates immune and cardiovascular depression or maintenance following injury.

Different immune responses to various disease entities have been shown in experimental and clinical studies. Trauma and sepsis severity is known to affect pathophysiological mechanisms $[2-4,12]$. In the present study, diseases were categorized into five groups (acute 
coronary syndrome, CABG surgery, sepsis, trauma, and COPD exacerbation). Within those categories severity was based on APACHE (Acute Physiology and Chronic Health Evaluation) score. Specific scoring systems (that is, ISS for trauma) were not mentioned, possibly limiting the conclusiveness of the data.

In clinical conditions (in contrast to experimental conditions), genetic background and comorbidities vary between critically ill patients, certainly affecting outcome. In the present study, chronic health conditions (that is, AIDS, cirrhosis, hepatic failure, lymphoma and leukemia, and tumors with metastases) were registered. Potentially relevant comorbidities (for example, diabetes) were not included.

Long-term medication as well as ICU medication (that is, heparin, cyclooxgenase inhibitors, steroids, and immunosuppressants) may alter immune responses and should be considered potential confounders. In this study, however, only immunosuppressants were registered.

Most studies investigating gender-specific outcome and mortality are retrospective, involving data from large registries. Despite enrolling huge numbers of patients, those studies are subject to limitations and constraints. There is no control over comprehensiveness or detail of data recorded, and information important for gender analysis (that is, hormone plasma levels, state of the estrus cycle, and pre- versus postmenopausal status) is not documented. To enhance data relevance, consideration of those potential confounders would require prospective registration of gender-specific parameters.

Because clinical studies suggest that females require less ICU treatment in comparison with males [14], incorporating ICU patients may reflect a selection bias of females with reduced prognosis in comparison with the overall female population. It is also important to consider age and hormonal status when investigating outcome in critically ill patients. Specifically designed prospective studies are required to better define the exact role of gender and sex hormones in the clinical arena. Female gender itself cannot be considered a protective factor in critically ill patients. Continued research into potential sex hormone-based differences may close the gap between bench and bedside and ultimately promote therapeutic interventions to improve outcomes in males and females. In this respect, individualized estrogen treatment should be based on actual hormonal status immediately after injury.

\section{Abbreviations}

CABG, coronary artery bypass graft; COPD, chronic obstructive pulmonary disease; ICU, intensive care unit; ISS, Injury Severity Score.

\section{Competing interests}

The authors declare that they have no competing interests.

\section{Acknowledgments}

The authors wish to thank Bobbi Smith for her skill and assistance in preparing this commentary. This work was funded by National Institutes of Health grants 5 RO1 GM037127 and 5 RO1 GM39519.

Published: 13 June 2012

\section{References}

1. Mahmood K, Wahidi MM, Eldeirawi K: Association of gender with outcomes in critically ill patients. Crit Care 2012, 16:R92.

2. Angele MK, Schwacha MG, Ayala A, Chaudry IH: Effect of gender and sex hormones on immune responses following shock. Shock 2000, 14:81-90.

3. Angele MK, Schneider CP, Chaudry IH: Latest results in hemorrhagic shock: Bench to bedside. Crit Care 2008, 12:218-230.

4. Yu H-P, Chaudry IH: The role of estrogen and receptor agonists in maintaining organ function following trauma-hemorrhage. Shock 2009, 31:227-237.

5. Sperry JL, Minei JP: Gender dimorphism following injury: making the connection from bench to bedside. J Leukoc Bio/ 2008, 83:499-506.

6 Gannon CJ, Napolitano LM, Pasquale M, Tracy JK, McCarter RJ: A statewide population-based study of gender differences in trauma: validation of a prior single-institution study. J Am Coll Surg 2002, 195:11-18.

7. George RL, McGwin G Jr., Windham ST, Melton SM, Metzger J, Chaudry IH: Age-related gender differential in outcome after blunt or penetrating trauma. Shock 2003, 19:28-32

8. Deitch EA, Livingston DH, Lavery RF, Monaghan SF, Bongu A, Machiedo GW: Hormonally active women tolerate shock-trauma better than do men: a prospective study of over 4000 trauma patients. Ann Surg 2007, 246:447-453

9. Frink M, Pape HC, van Griensven M, Krettek C, Chaudry H, Hildebrand F: Influence of sex and age on MODS and cytokines after multiple injuries Shock 2007, 27:151-156.

10. Kerby JD, McGwin G Jr., George RL, Cross JA, Chaudry IH: Sex differences in mortality after burn injury: results of analysis of the National Burn Repository of the American Burn Association. J Burn Care Res 2006, 27:452-456.

11. George RL, McGwin G Jr., Schwacha MG, Metzger J, Cross JM, Chaudry IH: The association between sex and mortality among burn patients as modified by age. J Burn Care Rehabil 2005, 26:416-421.

12. Frink M, Hsieh YC, Hu S, Hsieh CH, Pape HC, Choudhry MA, Schwacha MG, Bland Kl, Chaudry IH: Mechanism of salutary effects of finasteride on posttraumatic immune/inflammatory response: upregulation of estradiol synthesis. Ann Surg 2007, 246:836-843.

13. Hersh AL, Stefanick ML, Stafford RS: National use of postmenopausal hormone therapy: annual trends and response to recent evidence. JAMA 2004, 291:47-53.

14. Mostafa G, Huynh T, Sing RF, Miles WS, Norton HJ, Thomason MH: Genderrelated outcomes in trauma. J Trauma 2002, 53:430-434.

doi:10.1186/cc11365

Cite this article as: Angele MK, et al:: Does gender influence outcomes in critically ill patients? Critical Care 2012, 16:129. 